\title{
The depth of sorbath penetration in periodic adsorption processes
}

\author{
M. B. Kravchenko.
}

Odessa National Academy of Food Technology, Kanatnaya str. 112, Odesa, 65039, Ukraine.

E-mail: kravtchenko@i.ua.

The depth of sorbate penetration into the adsorbent grains is a new dimensional criterion for estimating efficiency of using the adsorbent in periodic adsorption and desorption processes. A concrete example shows the possibility of using this criterion in preliminary calculations of oxygen production plants working by the pressure swing adsorption method.

Key words: Adsorption, Oxygen, Short-cycle adsorption, PSA, VPSA.

\section{Глибина проникнення сорбату в періодичних процесах адсорбції}

\section{М. Б. Кравченко}

Одеська національна академія харчових технологій, вул. Канатна, 112, Одеса, 65039, Україна

Глибина проникнення сорбату в зерна адсорбенту - изе новий розмірний критерій для оиінки ефективності використання адсорбенту в періодичних процесах адсорбиї та десорбиії. На конкретному прикладі показана можливість його використання в попередніх розрахунках установок для виробництва кисню за допомогою методу короткоциклової безнагрівної адсорбиії.

Ключові слова: адсорбиія, кисень, короткочиклова безнагрівна адсорбичія. КБА.

(C) The Author(s) 2018. This article is an open access publication

This work is licensed under the Creative Commons Attribution 4.0 International License (CC BY) http://creativecommons.org/licenses/by/4.0/

\section{Introduction}

In the technical sciences, intuitive, dimensional criteria characterizing a particular physical process are widely used. Examples of such criteria are: the thickness of the boundary layer; velocity of sound; critical temperature; the mean free path of molecules, and so on.

In this paper, a new dimensional criterion is proposed - the depth of sorbate penetration into the adsorbent grain, which may be useful in preliminary calculations of the pressure swing adsorption plants.

This criterion is a direct analogue of the parameter widely used in electrical engineering - the depth of altering current penetration into a conductor or the skin depth.

Application of the proposed criterion is most advisable in the analysis of rapidly flowing, variables in the direction adsorption processes.

For the theoretical analysis of rapidly occurring sorption processes in the technical literature, use a kinetic coefficient of adsorption having the dimension $\left[\mathrm{c}^{-1}\right]$.

The equation of adsorption kinetics with kinetic coefficient of adsorption has the form:

$$
\frac{d a}{d \tau}=\beta\left(C_{0}-C^{\prime}\right)
$$

where, $a$ is the adsorption; $\tau$ is the time of adsorption; $\beta$ is the kinetic coefficient of adsorption; $C_{0}$ is the concentration of component in the entrance of adsorbent layer; $C$ ' is the concentration of the component in equilibrium with adsorbent.

This kinetic coefficient of adsorption is not very suitable for practical applications, since the actual time dependence of sorbate uptake by the grain of the adsorbent, as a whole, is not linear, and its linearization is possible only at the very beginning or at the very end of the adsorption process. Consequently, in the most important, from the practical point of view, modes of adsorption, the kinetic coefficient is not actually determined.

The proposed criterion is free from this drawback and can be uniquely determined for each batch of adsorbent.

\section{Material And Methods}

We consider the one-dimensional problem of diffusion and absorption of sorbate in a semi-infinite layer of the adsorbent. For the convenience to solve the problem, we place the origin of coordinates on the boundary of the adsorption layer, as shown in Figure 1.

If we assume that adsorption is described by the Henry isotherm, then such a problem reduces to solving a one-dimensional molecular diffusion equation.

This equation can be written in the form: 


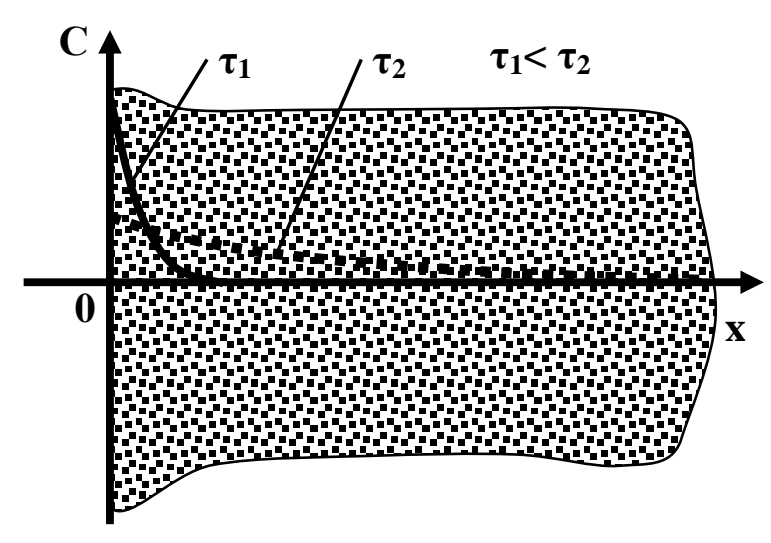

Figure 1. Sorbate adsorption in the adsorbent layer.

$$
D_{e} \frac{\partial^{2} C(x, \tau)}{\partial x^{2}}=K_{H} \frac{\partial C(x, \tau)}{\partial \tau},
$$

where, $C$ is the current molar concentration of the component in the gas that is in the pores of the adsorbent, $[\mathrm{kmol} / \mathrm{kmol}]$;

$D_{e}$ is the equivalent value of the sorbate diffusion coefficient in the adsorbent layer, taking into account the diffusion features in the porous body - the relative pore volume, the variable pore cross section, the presence of dead-end pores, etc., $\left[\mathrm{m}^{2} / \mathrm{s}\right]$;

$\tau$ is a time, [s];

$K_{H}$ is the dimensionless form of the Henry constant for the gas absorbed by the adsorbent.

The physical meaning of the dimensionless Henry constant is that it shows how many times the volume of absorbed gas is greater than the bulk volume of the adsorbent itself. Sometimes this value, by analogy with the absorption coefficient, is called the adsorption coefficient.

If we know the value of Henry's constant $K_{g}$ $\left[\mathrm{kmol} /\left(\mathrm{m}^{3} \cdot \mathrm{Pa}\right)\right]$, then at a given pressure it is easy to find the value of gas adsorption in a $\left[\mathrm{kmol} / \mathrm{m}^{3}\right]$. Multiplying the obtained adsorption value by the molar volume of the gas absorbed at a given pressure, we obtain the value of the dimensionless Henry constant:

$$
K_{H}=\left(K_{g} \cdot P\right) \frac{R T}{P}=K_{g} R T,
$$

here, $R$ is the universal gas constant, $[\mathrm{J} /(\mathrm{kmol} \cdot \mathrm{K})] ; T$ is the temperature, $[\mathrm{K}] ; P$ is the pressure, $[\mathrm{Pa}]$.

As can be seen from the last formula, the dimensionless Henry constant does not depend on the pressure of the adsorbed gas and is uniquely determined by the Henry constant.

We assume that $1 \mathrm{kmol}$ of pure sorbate is instantaneously supplied to the boundary of the adsorbent layer. The solution of this problem of adsorption can be represented in the form of a one-dimensional source function [1], which in the adopted notation has the form:

$$
C(x, \tau)=\frac{2}{\sqrt{2 \pi}} \sqrt{\frac{K_{H}}{D_{E} \cdot \tau}} \exp \left(-\frac{K_{H} \cdot x^{2}}{4 D_{E} \cdot \tau}\right),
$$

It is easy to verify that the total amount of sorbate in the adsorbent bed remains constant, and over time only its distribution inside the adsorbent bed changes. Indeed, the total amount of sorbate inside the adsorbent layer is:

$$
\begin{gathered}
\frac{2}{\sqrt{2 \pi}} \int_{0}^{+\infty} \exp \left(-\frac{u^{2}}{2}\right) d u=1, \\
\text { where, } u=\sqrt{\frac{K_{H} \cdot x^{2}}{D_{E} \cdot \tau}}=\frac{x}{\sigma} .
\end{gathered}
$$

We call a value,

$$
\sigma=\sqrt{\frac{D_{E} \cdot \tau}{K_{H}}},
$$

having the dimension of length, is the depth of the sorbate penetration into the adsorbent grain.

The physical meaning of this value is fairly obvious, and can be easily derived from equation (4). At a distance from the surface of the adsorbent,

$$
\sqrt{2 \cdot} \cdot \sigma
$$

the sorbate concentration in $e=2.718$ times lower than the sorbate concentration on the surface of the adsorbent grains.

The convenience of the proposed parameter for estimating the course of adsorption processes is explained by the fact that practically all adsorption processes that are used in technique are periodic. Therefore, the time of the adsorption process, which is necessary to calculate the depth of sorbate penetration, is always known - this is the time of adsorber operation in the adsorption regime, or the time of regeneration of the adsorbent.

For effective operation of the adsorption apparatus, the depth of the sorbate penetration into the grain of the adsorbent must be greater than the size of the grains themselves. If the depth of sorbate penetration into the adsorbent is less than the characteristic size of the adsorbent grains, the adsorption capacity of the adsorbent will not be fully utilized, and the adsorption apparatus with such adsorbent will not work efficiently.

It is very important that the amount of sorbate absorbed in the adsorbent layer, of thickness $\mathrm{x}$, is described by the error function:

$$
Q(x, \tau)=\frac{2}{\sqrt{2 \pi}} \int_{0}^{\pi / \sigma} \exp \left(-\frac{u^{2}}{2}\right) d u .
$$

This makes it possible not to calculate the values of this integral, but to use already available tables of its values, which are usually given in the manuals on mathematical statistics.

Therefore, without making calculations, it can be argued that $68.3 \%$ of the sorbate absorbed in the adsorbent layer with depth of $\sigma$. In a depth of $2 \sigma$ will absorbed $95.4 \%$ of the sorbate, and in the layer of depth $3 \sigma-99.7 \%$ of the sorbate will be absorbed, that is, practically entire sorbate absorbed by the adsorbent.

If the sorbate is fed not in one portion but in several, it is obvious that later portions of the sorbate will penetrate to a lesser depth. In this case, it can be argued that more than $68.3 \%$ of the sorbate absorbed by the adsorbent will be absorbed in the adsorbent layer with a depth $\sigma$.

If the surface of the adsorbent grains is not flat, but convex, the proportion of the adsorbent, absorbed near the surface of the grains, will become even greater.

Therefore, it can be argued that for an arbitrary character of the change in sorbate concentration, on the surface of the adsorbent grains having a spherical or cylindrical shape, more than $70 \%$ of the sorbate, absorbed 
by the adsorbent, will be absorbed in the surface layer with a depth $\sigma$. In a layer of depth $2 \sigma$, more than $95 \%$ of the sorbate will be absorbed, that is, practically the entire sorbate that is absorbed by this adsorbent.

Let us demonstrate the application of the proposed criterion for the analysis of processes in a pressure swing adsorption unit designed to produce oxygen.

To absorb nitrogen in such installations, synthetic zeolites are usually used. The isotherm of nitrogen adsorption by zeolites at pressures below 10 bars is practically linear, so we can use the data available in the literature to determine the Henry constant. The typical value of the Henry constant under nitrogen absorption by a CaA zeolite is $K_{g}=2.0 \cdot 10^{-2} \mathrm{nsm}^{3} /(\mathrm{g} \cdot \mathrm{mmHg})$ [2], or in units more convenient for us $-K_{g}=4.7 \cdot 10^{-6} \mathrm{kmol} /\left(\mathrm{m}^{3} \mathrm{~Pa}\right)$. Hence, we find the value of the dimensionless Henry constant $K_{H}=11.7$.

The diffusion coefficient of nitrogen in air can be determined from the approximate empirical formula [3]:

$$
D=\frac{0,437 \cdot T^{3 / 2}}{P\left[\left(\frac{V_{a}}{C_{a}}\right)^{1 / 3}+\left(\frac{V_{k}}{1-C_{a}}\right)^{1 / 3}\right]} \sqrt{\frac{C_{a}}{\mu_{a}}+\frac{1-C_{a}}{\mu_{k}}}
$$

where $T$ is the temperature, $[\mathrm{K}] ; P$ is the pressure of the mixture, $[\mathrm{Pa}] ; C_{a}$ is the molar concentration of nitrogen; $V_{a}$ and $V_{k}$ are the molar volumes of the components of the mixture, $\left[\mathrm{m}^{3} / \mathrm{kmol}\right] ; \mu_{\mathrm{a}}$ and $\mu_{\mathrm{k}}$ are the molecular masses of the mixture components.

The equivalent value of the diffusion coefficient in porous bodies taking into account the relative pore volume, the variable pore cross section, the presence of dead-end pores, etc., is found by the formula [4]:

$$
D_{E}=\frac{D \cdot \varepsilon}{\xi},
$$

where $\mathrm{D}$ is the diffusion coefficient of the absorbed gas in the gas mixture being separated, $\left[\mathrm{m}^{2} / \mathrm{s}\right]$;

$\varepsilon$ is the porosity or relative volume of the volume occupied by the pores; for most porous bodies permeable to gases, the porosity value is close to 0.3 ;

$\xi$ is the diffusion resistance coefficient, taking into account the variable pore cross section, the presence of dead-end pores, and the like. The value of this coefficient is usually determined experimentally, and is in the interval from 4 to 9 [4].

In order to determine the equivalent value of the diffusion coefficient, we use the experimental value of the equivalent diffusion coefficient of nitrogen in the pores of the zeolite at atmospheric pressure, which is reviewed in [2]. This value of the equivalent diffusion coefficient turned out to be $2.4 \cdot 10^{-6} \mathrm{~m}^{2} / \mathrm{s}$. The value of the diffusion resistance coefficient, adjusted from this value of the equivalent diffusion coefficient, was 7.7. Using this value of the diffusion resistance coefficient and equations (6) and (8), we find the dependence of the depth of penetration of the sorbate on the pressure and time of the process.

Figure 2 shows the calculated values of the penetration depth of nitrogen into the synthetic zeolite, depending on the pressure and time of the process. The above graph can be used for preliminary calculations of pressure swing adsorption plants designed to extract oxygen from air.
To obtain a relatively high concentration of oxygen more than $90 \%$, it is necessary to ensure, as far as possible, a more complete regeneration of the adsorbent. This is possible only if the depth of penetration of nitrogen into the zeolite is greater than two radii of the zeolite grains. Under this condition, an almost complete regeneration of the adsorbent inside the zeolite grains will be ensured, more precisely, more than $95 \%$ of the nitrogen absorbed in the zeolite will be removed from this zeolite during the regeneration process.

Thus, the effective operation of the pressure swing adsorption unit to produce oxygen is possible only when the characteristic grain size of the adsorbent is much smaller than the penetration depth of the absorbed component nitrogen. The graph shown in Fig. 2 allows, knowing the grain size of the adsorbent used, to determine the period of operation of the adsorbers, and, conversely, by the adsorber operating time, determine the maximum grain size of the adsorbent suitable for this installation.

It can be seen from the graph shown in Fig. 2, that with a constant period of operation time, the depth of nitrogen penetration into the zeolite increases with decreasing regeneration pressure. This suggests that vacuum regeneration of the adsorbent is preferable to regeneration at atmospheric pressure.

The results obtained are in good agreement with the data published in the technical literature. The experience of operating the pressure swing adsorption plants, summarized in the review [2], suggests that a relatively high oxygen concentration, more than $90 \%$, is easily achieved in installations using microspherical adsorbent granules with a diameter is less than $1 \mathrm{~mm}$. The same concentration of production oxygen is difficult to achieve using the zeolite having granules of $2-3 \mathrm{~mm}$ in size, and it is practically not achievable when use the zeolites with a granules size of more than $3 \mathrm{~mm}$.

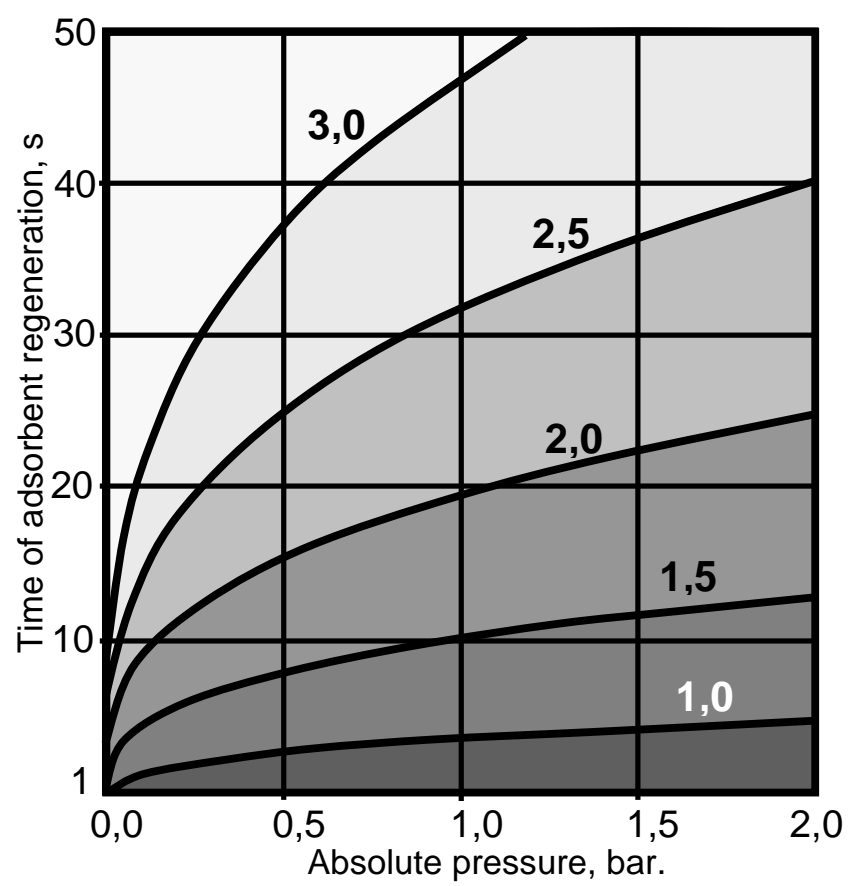

Figure 2. Dependence of the depth of nitrogen penetration into the grain of $\mathrm{CaA}$ adsorbent (in $\mathrm{mm}$ ) for different process times and different values of the absolute pressure of the adsorbent 
It would be a mistake to consider that the smaller the size of the adsorbent grains, the more efficiently the pressure swing adsorption system works. If the process of regeneration of the adsorbent precedes the better, the smaller size of adsorbent grains, then the impurity absorption process passes well on the adsorbent with larger grains. Indeed, for a given adsorption time, the concentration of the absorbed component on the surface of the larger grains will always be smaller, since a large fraction of absorbed substance takes up the inside of the grains. A lower concentration of the absorbed component on the grain surface means that it is easier to obtain a higher concentration of the product gas at the outlet of the adsorber by means of an adsorbent with coarse grains.

Therefore, for the given grain size of the adsorbent, there are an optimal period of absorption and the optimal adsorbent regeneration time.

It follows from the above analysis that the high purity of oxygen obtained by the pressure swing adsorption method is easier to obtain in a plant with three or more adsorbers, since only in such installations it is possible to organize the operation so that the regeneration time of the adsorbent is substantially greater than the nitrogen absorption time.

The experience of operating the pressure swing adsorption plants for obtaining oxygen confirms the drawn conclusions. It is in units with three or four adsorbers and vacuum regeneration that it is possible to achieve the greatest efficiency of the process of releasing oxygen from the air.

\section{Conclusion}

A new dimensional criterion for estimating periodic processes of gas adsorption and desorption is proposed the depth of sorbate penetration into the adsorbent.

It is shown that it can be used for preliminary calculations of oxygen production plants using the pressure swing adsorption method.

\section{References and notes}

1. Lykov A.V. (1967) Theory of heat conductivity. Moskow: High School, 502 p. (in Russian).

2. Glupanov VN, Shmulyatsky Yu.I., Seregin Yu.A., Brekhner S.A. (1991) Obtaining oxygen and nitrogen by adsorption air separation. Overview information. Series XM-14, CINTICHEMNEFTEMASH, 45 p. (in Russian).

3. Handbook on the physical and technical bases of cryogenics (1985) Edited by: M.P. Malkov, I.B. Danilov, A.G. Zeldovich, A.B. Fradkov; Ed. M.P. Malkov. Moscow: Energoatomizdat, 432 p. (in Russian).

4. Dytnersky Yu.I. Brykov V.P. Gagranov G.G. (1991) Membrane gas separation. Moscow: Chemistry, 344 p. (in Russian). 